\title{
A proteção social no campo da seguridade à luz do discurso solidarista
}

\section{Social protection in the field of security according the solidarist speech}

Patrícia Fontes Marçal Faculdade Estácio de Porto Alegre, Porto Alegre/RS, Brasil. Instituto Brasileiro de Gestão de Negócios, IBGEN, Porto Alegre/RS, Brasil

DiNORA TEREZA ZuCCHETTI Universidade Feevale, FEEVALE, Novo Hamburgo/RS, Brasil

Resumo O ensaio de revisão bibliográfica e estudo de legislações de base tem por objetivo demonstrar a forma como o Discurso Solidarista oferece substrato para a emergência do conceito de Seguridade Social no Brasil contemporâneo. Parte de uma breve apresentação histórica da Previdência Social buscando, a partir daí, situar o atual sistema de Seguridade Social brasileiro constituído pelo tripé da Previdência Social, Saúde e Assistência Social. Atualiza questões de longa data - patrimonialismo, verticalidade e exclusão social - que produzem, ainda hoje, marcas profundas nas populações pior situadas social e economicamente, e que sofrem, também, os reflexos de um modelo de sociedade subserviente ao capitalismo internacional, globalizado. Mesmo mediante um quadro histórico e econômico pouco promissor, o ensaio reafirma a proteção da cidadania enquanto direito constitucional. Contudo, não se exime em chamar a atenção para os limites de uma proteção social onde o conceito de solidariedade presente no Discurso Solidarista, de caráter jurídico-político é limitante e limitador numa sociedade onde o controle social é de baixíssima intensidade. 
O método científico adotado foi o de levantamento e análise legal/ constitucional da matéria pertinente ao tema.

Palavras-chave: Seguridade Social. Proteção Social. Discurso SoliDARISTA.

Abstract The essay on bibliographic review and study of basic legislation aims to demonstrate how the Solidarist Discourse offers a substrate for the emergence of the concept of Social Security in actual Brazil. Part of a brief historical presentation of Social Security, seeking, from there, to locate the current Brazilian Social Security system constituted by the tripod of Social Security, Health and Social Assistance. It updates long-standing issues - patrimonialism, verticality and social exclusion - that still produce profound imprints on populations that are worse off socially and economically, and which also suffer from the reflexes of a model of society subservient to globalized, international capitalism. Even through an unpromising historical and economic framework, the essay reaffirms the protection of citizenship as a constitutional right. However, it is not exempt from drawing attention to the limits of a social protection where the concept of solidarity present in the Solidarist Discourse, of juridical and political character, is limiting and limiting in a society where social control is of very low intensity. The scientific method adopted was the collection and legal and constitutional analysis of the pertinent subject matter.

Key-words: Social Security. Social Protection. Solidarist speech.

\section{INTRODUÇÃO}

Eu não acredito em caridade. Eu acredito em solidariedade. Caridade é tão vertical: vai de cima para baixo. Solidariedade é horizontal: respeita a outra pessoa e aprende com o outro. A maioria de nós tem muito o que aprender com as outras pessoas.

\section{- Eduardo Galeano}


O presente texto tem por objeto a Seguridade Social como sistema formado pelo "tripé" da Previdência Social, da Assistência Social e da Saúde à luz da atual Constituição Federal de 1988. Busca compreender, na revisão da literatura, a construção e a evolução do conceito de proteção social a partir da evolução do Direito do trabalho.

Por séculos, várias foram as formas violentas de opressão, castigos, precarização do ambiente laboral que trouxeram sequelas físicas, morais, patrimoniais, psíquicas, entre outras aos trabalhadores. Danos produzidos ao longo do tempo demandaram medidas de proteção àqueles sacrificados pela necessidade social de sobrevivência, relativamente às suas escassas condições de vida. Desse contexto, emergiram as leis de proteção voltadas, especialmente, aos que sofrem as consequências de um sistema de abuso, jugo e subserviência.

Quando se estuda a história do trabalho, também se estuda a história da escravidão e dos instrumentos de tortura utilizados para forçar o trabalho servil. Tal constatação nos coloca diante da heterogeneidade da história do trabalho e, por conseguinte, dos modos de produzir conceitos em torno dele.

\footnotetext{
$\mathrm{Na}$ Antiguidade Clássica, tanto na Grécia em seu apogeu, por volta do século V A.C., quanto na Roma Imperial, o trabalho obedeceu a duas vertentes básicas: as elites dominantes ocupavam-se exclusivamente do trabalho intelectual, artístico, especulativo ou político. De outro lado, as funções consideradas subalternas por sua natureza rústica e penosa ("trabalho braçal") eram desempenhadas pela mão de obra escrava, obtida nas guerras de conquista. Os vencidos eram transformados em escravos (ORNELLAS e MONTEIRO, 2006, p. 552 e 553).
}

Era comum, no trabalho braçal, a sua imposição pelo castigo caso os executores incorressem em erros e transgressões, ou seja, uma forma de punição. Para exemplificar, recorremos a Camus quando retrata o esforço inútil de Sísifo que, mesmo laborando de forma árdua, nunca terá seu trabalho concluído, sequer recompensado. 
Os deuses tinham condenado Sísifo a rolar um rochedo incessantemente até o cimo de uma montanha, de onde a pedra caía de novo por seu próprio peso. Eles tinham pensado, com as suas razões, que não existe punição mais terrível do que o trabalho inútil e sem esperança (CAMUS, s.d., p. 85).

Ao retratar esse mito, Camus alerta para o trabalho repetitivo, exaustivo, como um fardo a ser carregado pelo restante das vidas, sem vislumbre de uma saída. Assim, constituiu-se o ideário que permeou a concepção de trabalho na Antiguidade e que se perpetua na Modernidade.

A Revolução Industrial consolidada nos séculos XVIII e XIX, marco do nascimento do capitalismo, somente reiterou essa ênfase diante da ânsia de se produzir riqueza em grande escala e em menor tempo. Em outras palavras, embora o acesso à tecnologia que, em determinados casos facilitou o trabalho do operário, representou, também, uma sobrejornada, na medida em que ele se tornava responsável por cuidar dos equipamentos, mantendo-os funcionando, para o bem da produção.

Ou ainda:

A fim de que o trabalho acumulado nos bens de produção assuma a função de capital é preciso que se converta em instrumento de exploração do trabalho assalariado. Em vez de coisa, o capital é relação social, relação de exploração dos operários pelos capitalistas. As coisas — instalações, máquinas, matérias-primas etc. constituem a encarnação física do trabalho acumulado para servir de capital, na relação entre o proprietário dessas coisas e os operários contratados para usá-las de maneira produtiva. O capital se encarna em coisas: instrumentos de produção criados pelo homem. Contudo, no processo de produção capitalista, não é o trabalhador que usa os instrumentos de produção. Ao contrário: os instrumentos de produção - convertidos em capital pela relação social da propriedade privada — é que usam o trabalhador. Dentro da fábrica, o trabalhador se torna um apêndice da máquina e se subordina aos mo- 
vimentos dela, em obediência a uma finalidade - a do lucro - que lhe é alheia. O trabalho morto, acumulado no instrumento de produção, suga como um vampiro (a metáfora é de Marx) cada gota de sangue do trabalho vivo fornecido pela força de trabalho, também ela convertida em mercadoria, tão venal quanto qualquer outra (MARX, 1996, p. 34).

Marx chama a atenção para a dimensão da sobrevida dos membros das famílias e, não somente, a do seu responsável no que tange à exploração do trabalho capitalista.

A sociedade capitalista transformou o trabalho de condição essencial da vida humana em algo alienado e fetichizado. O trabalho pode ser considerado uma mercadoria que o trabalhador vende o tempo, além de estar disponível para o trabalho, sendo o seu corpo a própria força de trabalho (SOUZA, 2012, p. 28 e 29).

O apogeu do trabalho como valor de troca sobre o seu valor de uso, o fortalecimento de diversos campos de domínios de poder, especialmente nos campos político e econômico no bojo da Primeira Grande Guerra, fomentaram a criação da Organização Internacional do Trabalho (OIT), em 1919, a qual asseverava que a paz mundial passava, necessariamente, pela justiça social. Igualmente, mediante cenários de conflito social o Brasil, entre outros países, aderiu à Organização e, na medida desse alinhamento o país passou a ser pressionado por uma regulamentação no campo do trabalho. Urgia, entre outros, a necessidade de proteção no ambiente laboral contra os desmandos e os abusos cometidos contra a classe trabalhadora que se via explorada e pouco remunerada.

No bojo dessa exploração, o desamparo dos trabalhadores na sua velhice, o aparecimento e agravamento de doenças e acidentes, no e do trabalho, além de outras disfunções oriundas de um ambiente hostil e nocivo à saúde a demandar pela criação de um campo de proteção no âmbito da Previdência Social. Leis e normas foram sendo produzidas 
para a proteção do sujeito trabalhador, incluindo o período de sua vida laboral inativa.

\section{A Previdência Social: ontem e hoje}

Tratando-se como castigo às supostas transgressões cometidas pelo homem fabris (da fábrica), uma vez em desacordo com as ordens dos empregadores, emergia a necessidade, após várias regulamentações, como exemplo o benefício à aposentadoria dos ferroviários em 1923, os Institutos de Aposentadoria e Pensão (IAP's), em 1933, entre outros, para assegurar-se uma proteção efetiva contra essa violenta relação. Questões como doenças laborais decorrentes do embate mercado versus trabalho, ausência de segurança e higiene ambiental, entre outras, eram temas a serem enfrentados.

Ao se destacar a importância da proteção social no campo do trabalho devido à forma como foi estabelecido (escravidão, opressão, submissão e castigo) e, tendo em vista que este na sua modalidade de emprego afirma-se como um importante meio exploratório da atividade humana é que foi necessário buscar pela proteção social no âmbito da Previdência. Constituída num sistema, visava a garantir uma segurança pós-trabalho, na proteção à velhice e, em atividade, na iminência de acidentes, na morte e mediante os direitos à família, no auxílio reclusão, no caso de o operário cometer delito, entre outros benefícios.

A Previdência, sob os auspícios da OIT (2011, p. xxv) e em relação ao piso de proteção social recomenda que se constitua:

O conceito "pisos de proteção social", no plural, refere-se às adaptações da abordagem global às circunstâncias específicas de cada país. Certamente, este enfoque não deve ser considerado como uma solução mágica para os problemas sociais do mundo. Porém um vasto leque de experiências internacionais indica que os países podem progredir mais rapidamente na redução da pobreza e da exclusão social se tais questões forem abordadas de forma coerente e consistente, começando 
pela extensão horizontal do acesso aos serviços sociais básicos e à segurança de renda. A noção de Piso de Proteção Social está ancorada no princípio fundamental de justiça social e no direito universal de todos à seguridade social e a um padrão de vida digno. As disposições estabelecidas no marco conceitual do Piso referem-se a uma série de direitos constantes na Declaração Universal de Direitos Humanos. A ideia principal é que nenhum cidadão deve viver abaixo de um determinado nível de renda e que ao menos o acesso aos serviços sociais básicos deve ser universal. O Piso de Proteção Social está fortemente ligado à Agenda do Trabalho Decente. Para se ter sucesso na luta contra a pobreza, a privação e as desigualdades, não se pode atuar de forma isolada. Com o objetivo de obter uma redução eficaz da pobreza, suas estratégias devem ser acompanhadas por medidas tais como o reforço das instituições sociais e laborais e a promoção de ambientes macroeconômicos favoráveis ao emprego.

Para o autor Polignano (2001, p. 3), antes das recomendações da OIT, questões acerca do cuidado com os trabalhadores eram inexistentes. "Até 1850, as atividades de saúde pública estavam limitadas ao seguinte: a) delegação das atribuições sanitárias às juntas municipais; b) controle de navios e saúde dos portos." O Controle Sanitário era o mínimo e, mínimo, também era o número de profissionais da saúde aptos a exercerem a função; ausentes, também, eram as preocupações sobre a saúde no trabalho. ${ }^{1}$

Foram mais de 80 anos até a criação do Ministério da Educação e Saúde Pública, em 1930, resultado da desintegração das atividades do Departamento Nacional de Saúde Pública, vinculado ao Ministério da Justiça. Desse desmembramento, a fiscalização de produtos de origem

1 “Em 1808, Dom João VI fundou, na Bahia, o Colégio Médico - Cirúrgico no Real Hospital Militar da Cidade de Salvador - e, no mês de novembro do mesmo ano, foi criada a Escola de Cirurgia do Rio de Janeiro, anexa ao real Hospital Militar", lembra Polignano (2001, p. 3). 
animal passou para o Ministério da Agricultura (1934), e a higiene e segurança do trabalho (1942) ficou vinculada ao Ministério do Trabalho.

Nas primeiras décadas do século XX, empregados de uma mesma empresa, sem a participação do poder público, instituíam fundos de auxílio mútuo, nos quais também o empregador colaborava, de forma a garantirem meios de subsistência quando não fosse possível se manterem no trabalho por motivos de doença ou velhice. A assunção do Estado na gerência do sistema previdenciário brasileiro foi lenta e gradual. O primeiro ato governamental de intervenção nesta área ocorreu em 1923, com a promulgação da Lei Eloy Chaves, determinando a criação de uma Caixa de Aposentadorias e Pensões - CAP, para os trabalhadores de ferrovias. Entretanto, eram sociedades civis em que a ingerência do setor público era mínima, cabendo sua administração a um colegiado composto de empregados e empregadores. As CAPs expandiram-se para outras categorias funcionais assalariadas, chegando a serem instaladas cerca de 180 caixas de aposentadorias no Brasil. [...] A primeira instituição desse tipo, o Instituto de Aposentadorias e Pensões dos Marítimos - IAPM, surgiu em 1933 e destinava-se a agregar as CAPs dos marítimos. Ao longo da década, foram criados outros institutos para as categorias dos comerciários (1934), bancários (1935), industriários (1938) e os empregados em transportes e cargas (1938) (BATICH, 2004, p. 33).

Somente em 1966 consolidou-se a unificação do sistema previdenciário com a criação do Instituto Nacional de Previdência Social (INPS), que agregou todos os Institutos de Aposentadorias e Pensões (IAPs) deixando, definitivamente, de haver diferenças entre os segurados do setor privado da economia, no tocante à instituição previdenciária que os assistia. Nos anos 70, foram instituído novos tipos de benefícios previdenciários, como o salário família e o salário maternidade e, ainda, foram incluídas no sistema categorias que antes não tinham qualquer 
cobertura, como a do jogador de futebol profissional, os trabalhadores autônomos e temporários, a empregada doméstica e o trabalhador rural.

É com a Constituição Federal de 1988, no artigo 193 da Carta, que é afirmada a seguridade social como sendo formada por um conjunto integrado de ações de iniciativa dos poderes públicos e da sociedade, destinada a assegurar os direitos relativos à saúde, à previdência e à assistência social. Nesse "guarda-chuva" ou "tripé" merece destaque a construção de um sistema que busca garantir uma atenção universalizante e universal.

O termo Seguridade Social é um conceito estruturante das políticas sociais cuja principal característica é de expressar o esforço de garantia universal da prestação de benefícios e serviços de proteção social pelo Estado. Neste sentido, sua base de financiamento é bem mais ampla que a do seguro social, conceito que orientou a política previdenciária brasileira desde os anos de 1920, organizada sob inspiração do modelo alemão, criado por Bismark na segunda metade do século XIX. É sabido que a expressão Seguridade Social tem origem anglo-saxônica, tendo por referência certas políticas do início do século XX [aparecendo] pela primeira vez no documento de lançamento do Social security act, que instituiu a Previdência Social americana, em 1935 (DELGADO, JACCOUD e NOGUEIRA, s.d., p. 21).

Assim é a seguridade social, no caso brasileiro, no que diz respeito ao campo da saúde, e tendo em vista que a Constituição Federal (art. 196) assevera que a saúde é direito de todos e dever do Estado. Ela é garantida mediante políticas sociais e econômicas que visam à redução do risco de doenças e de outros agravos. O acesso é universal e igualitário nas ações e serviços de promoção, proteção e recuperação que vêm expressos enquanto direito fundamental por meio do Sistema Único de Saúde (SUS). Este tem sua concepção ancorada na formulação de um modelo de saúde voltado para as necessidades da população, procura resgatar o compromisso do Estado para com o bem-estar social, espe- 
cialmente, no que concerne à saúde coletiva, consolidando o sistema de saúde como um dos direitos de cidadania.

Quanto à Previdência, conforme o artigo 201 da Lei $n^{\circ} .8 .213$ de 24 de julho de 1991, será organizada sob a forma de regime geral, de caráter contributivo e de filiação obrigatória, observados os critérios que preservam o equilíbrio financeiro e atuarial. Embora voltada a todos, esses "todos" serão os que contribuírem para uma proteção universalizante porque, objetivando o princípio equitativo/igualitário, aqueles que contribuírem serão protegidos pela Previdência. Entre as coberturas estão os direitos à aposentadoria, pensão por morte, auxílio reclusão, benefício saúde, proteção à maternidade, desemprego involuntário, entre outros.

$\mathrm{Na}$ Carta Política atual também está definida a assistência social, determinada no artigo 203, a qual será prestada a quem dela necessitar, independentemente de contribuição à seguridade social. Nesse caso, os beneficiários são os idosos e os portadores de deficiência que terão garantido um salário mínimo mensal, caso não tenham como prover por si a sua subsistência ou se esta não for garantida por sua família. Outros recursos são reservados aos piores situados, entre eles, trabalhadores em regime de auxílio-saúde. Observa-se, no texto, uma proteção de tipo universalizante, de caráter compensatório, voltada para todos que dela necessitarem. O Sistema Único de Assistência Social (SUAS) na busca por efetividade operacionaliza as ações da assistência social a partir dos níveis de proteção social básica e especial.

Segundo Castro (2012), a seguridade social, assim expressa, tipifica a proteção social desde a ideia força de solidariedade. Destaca voltar-se para indivíduos, famílias e grupos desde que identificadas situações de dependência e/ou vulnerabilidade, entre as quais cita: a incapacidade de ganhar a vida por conta própria em decorrência de fatores externos, independentes da vontade individual, vulnerabilidades devido ao ciclo vital: infância e velhice, por exemplo, e o risco, no caso de acidentes, à invalidez, entre outros.

No que tange à proteção social, percebe-se que ela está estampada na pauta constitucional, voltada para todos os que dela necessitar, tratando-se de uma proteção universal (saúde), compensatória (assistência) e obrigacional (previdência). 


\section{O discurso SOlidarista NA base da PROTEÇÃo NO CONCEITO DE SEGURIDADE SOCIAL}

Diante do quadro aviltante de descompasso entre a realidade social de ricos e pobres, empregadores e empregados, capital e trabalho, não podemos deixar de problematizar a importância do discurso solidarista que surge com a Constituição Federal de 1988. A questão da igualdade e a emergência de um cidadão, sujeito de direito, pressupostos da Carta Maior, manifestam as condições para uma proteção social voltada ao conjunto da sociedade brasileira.

O discurso solidarista emerge no bojo das relações sociais existentes, criando um espaço social intermediário a fim de romper com as oposições tradicionais entre público e privado, Estado e sociedade civil, Estado e mercado, política e economia o que caracteriza, segundo o autor "uma nova forma de Estado que não pode mais ser classificada no quadro do Estado liberal (Estado protetor)". [...] É no âmbito de uma sociedade aberta, flexível e pluralista que se dão as condições para a emergência do direito de solidariedade, enquanto pratica alimentada pela sua própria complexidade social (FARIAS, 1998, p. 185).

Contudo, diante do emaranhado de relações de poder verticalizadas presentes na história do Brasil, a economia capitalista dependente, a gritante desigualdade social, como entender o significado da palavra "solidariedade" a fazer sociedade do ponto de vista de uma seguridade universal?

Segundo Rosso (2007), a etimologia da palavra solidariedade resgata sua origem associada ao étimo latino solidarium, que vem de solidum, soldum (inteiro, compacto). Define o termo como uma forma de pensar contrária ao egoísmo, firmando-se como um sentimento que leva os homens a se ajudarem mutuamente. Outros sentidos, em geral, remetem ao parentesco, convivência de irmãos, amor ao próxi- 
mo. Bem situado por Razeto (2005), na sua versão histórico-jurídica, a expressão solidariedade foi recuperada por agremiações profissionais enquanto expressão de compartilhamento entre pessoas no que tange às condições de vida e de trabalho afins e que, portanto, necessitam se organizarem em agrupamentos corporativistas e associações em geral.

No Estado clássico, de orientação liberal, a solidariedade não é posta como um princípio básico de atuação estatal. Embora não chegue a ser desestimulada, a liberdade é tomada como valor mais importante parecendo que a solidariedade é vista como preocupação da sociedade civil e não do Estado. No moderno Estado social, não se tem a mera pretensão de se garantir a liberdade, mas também de estimular a atuação de toda a sociedade em prol da igualdade. Daí a intenção de que a solidariedade deixe de ser apenas algo "desejável" para se tornar atuação obrigatória de toda a sociedade. $\mathrm{O}$ estado social não quer ser neutro e propõe-se a corrigir as desigualdades, posicionando-se como protetor do mais fraco. A solidariedade surge como justificadora dessa intenção (ROSSO, 2007, p. 204 e 205).

Nesse contexto, o discurso solidarista corresponde "a uma nova forma jurídico-política que assume uma nova função simbólica e uma nova capacidade de ação na sociedade", ou, ainda, segundo esse mesmo autor:

O discurso do solidarismo jurídico não é somente uma maneira de falar de direitos; ele é também um olhar sobre a sociedade como um todo e, por consequência, igualmente sobre a esfera política. [...] O discurso do solidarismo jurídico pretende ser o fundamento do Estado Democrático de Direito, ou seja, ele considera o campo político no Estado democrático como a vida indispensável, a única possível, para a realização do direito no seio de uma organização social (FARIAS, 1998, p. 197).

Para exemplificar o exposto, recorre-se ao acórdão do TRF da $4^{\mathrm{a}}$ Região, localizado no Rio Grande do Sul, cuja decisão interpreta o prin- 
cípio da solidariedade, à luz da Constituição Federal de 1988 conforme o artigo 195:

BRASIL. AC 5079350-52.2014.404.7100, D.E. 06/09/2016

Apelação/Remessa Necessária. RS

Data da Decisão: 31/01/2017

QUINTA TURMA

Relator: (Auxílio Paulo Afonso) TAÍS SCHILLING FERRAZ

Decisão: Vistos e relatados estes autos em que são partes as acima indicadas, decide a Egrégia 5a. Turma do Tribunal Regional Federal da $4^{\mathrm{a}}$ Região, por unanimidade, conhecer em parte do apelo do INSS e da remessa oficial e, nessa extensão, negar-lhes provimento, nos termos do relatório, votos e notas de julgamento que ficam fazendo parte integrante do presente julgado.

Ementa: PREVIDENCIÁRIO. APOSENTADORIA ESPECIAL. ATIVIDADE ESPECIAL. AGENTES NOCIVOS HIDROCARBONETOS E RUÍDO. EPIS E EPCS. FONTE DE CUSTEIO. CONCESSÃO. CORREÇÃO MONETÁRIA E JUROS DE MORA. FASE DE CUMPRIMENTO DE SENTENÇA. DIFERIMENTO.

1. O reconhecimento da especialidade e o enquadramento da atividade exercida sob condições nocivas são disciplinados pela lei em vigor à época em que efetivamente exercidos, passando a integrar, como direito adquirido, o patrimônio jurídico do trabalhador.

2. Até 28-04-1995 é admissível o reconhecimento da especialidade por categoria profissional ou por sujeição a agentes nocivos, admitindo-se qualquer meio de prova (exceto para ruído e calor); a partir de 29-04-1995 não mais é possível o enquadramento por categoria profissional, sendo necessária a comprovação da exposição 
do segurado a agentes nocivos por qualquer meio de prova até 05-03-1997 e, a partir de então, através de formulário embasado em laudo técnico, ou por meio de perícia técnica.

3. A exposição a hidrocarbonetos aromáticos e a níveis de ruídos superiores aos limites legais de tolerância vigentes à época do labor enseja o reconhecimento do tempo de serviço como especial.

4. Não havendo provas consistentes de que o uso de EPIs e EPCs neutralizava os efeitos dos agentes nocivos a que foi exposto o segurado durante o período laboral, deve-se enquadrar a respectiva atividade como especial.

5. Para a concessão de aposentadoria especial ou conversão de tempo exercido sob condições especiais em tempo de trabalho comum, previstas nos artigos 57 e 58 da Lei de benefícios, existe específica indicação legislativa de fonte de custeio: o parágrafo $6^{\circ}$ do mesmo art. 57 supracitado, combinado com o art. 22, inc. II, da Lei n. 8.212/91. Não há óbice, ademais, que se aponte como fonte do financiamento da aposentadoria especial e da conversão de tempo especial em comum as contribuições a cargo da empresa - não apenas previdenciárias pois o art. 195, caput e incisos, da Constituição Federal, dispõe que a seguridade social será financiada por toda a sociedade, de forma direta e indireta, nos termos da lei, mediante recursos provenientes dos orçamentos da União, dos Estados, do Distrito Federal e dos Municípios, e, dentre outras ali elencadas, das contribuições sociais do empregador, da empresa e da entidade a ela equiparada na forma da lei. Incidência do princípio da solidariedade (grifos das autoras).

6. Comprovada a exposição do segurado a agente nocivo, na forma exigida pela legislação previdenciária aplicável à espécie, possível reconhecer-se a especialidade do tempo de labor correspondente. 
Para a jurisprudência pátria, o artigo 195 da Constituição Federal dispõe que a seguridade social será financiada por toda a sociedade, de forma direta e indireta, e se dará mediante recursos provenientes dos orçamentos da União, dos Estados, do Distrito Federal e dos Municípios e, entre outras ali elencadas, das contribuições sociais do empregador, da empresa e da entidade a ela equiparada na forma da lei; é o que reza o disposto constitucional. Esse dispositivo demonstra a incidência do princípio da solidariedade, onde todos contribuem para o bem comum. São responsáveis, portanto, todos os entes da Federação, os trabalhadores e empregadores de forma solidária. Assim, o princípio da solidariedade representa a experiência da proteção que se aplica àqueles que da seguridade social vierem necessitar.

Nesse sentido, mesmo que prevaleça no país uma estrutura social elitizada e desigual, o discurso solidarista é ao mesmo tempo o mais poderoso agente do reconhecimento e ampliação do sufrágio universal, das liberdades políticas, dos direitos sociais e da democracia representativa.

\section{O DISCURSO SOLIDARISTA NA SEGURIDADE - ALGUMAS CONSIDE- RAÇÕES FINAIS}

Importante salientar que o Estado brasileiro delongou, e muito, a estabelecer os direitos mínimos de proteção ao longo de sua história. Desde a colonização, o modelo de economia instalado resultou na exploração de nosso país; a chegada da família Real ao Brasil, contudo, não foi capaz de transformar esse cenário. O retorno de Dom João a Portugal evidenciou a ausência de estruturas administrativas básicas para estabelecer um Estado que deferisse aos cidadãos que aqui residiam condições dignas de existência, ou seja, deixou o país sem proteção social mínima, inimaginável, portanto, pensá-la em caráter universal.

Posteriormente, na condição histórica de país de capitalismo periférico, dependente, protelaram-se decisões fundamentais no campo dos direitos humanos e sociais. Foram necessárias muitas novas Constituições Federais, adesão a tratados internacionais os mais diversos até a definição de um sistema de seguridade social. Isso permitiu, em tese, uma 
aproximação, mesmo que mínima, ao Estado de Bem-estar Social que, mais recentemente, nos anos 2000, ganhou ainda mais expressão com políticas sociais como o Bolsa Família, por exemplo. Contudo, mais recentemente, estamos a verificar retrocessos significativos nesse nunca atingível Estado de Bem-estar brasileiro, porque, novamente, vivemos descontinuidades na baixa coordenação entre as políticas sociais.

Entretanto, é inegável o avanço feito no campo da Seguridade Social que, na perspectiva de sistema, não mais se reduziu a um seguro, mas a uma política social mais ampla, mesmo que frágil. Castro (2012) aponta, para a abrangência, a qualidade e os serviços oferecidos como um sempre grande desafio. Linha de arguição compartilhada por Sposati (2013) ao alertar para a necessária interrelação das três políticas no ambiente da seguridade social tendo como frente de defesa a luta coletiva pela sua efetivação. Não sendo causa, será a seguridade social tanto mais factível quanto mais ligadas forem as três políticas que dela fazem parte.

Outra questão que merece reflexão é referente ao discurso solidarista e à possibilidade de ser confundido com paternalismo, protecionismo, entre outros qualificativos que borrem a perspectiva de direito social. Precisamos reafirmar a seguridade como conceito, valor, prática e formação enquanto um sistema de segurança contra riscos, perdas, danos que afetem a condição de vida não somente dos trabalhadores, mas dos desempregados, em que pese a dimensão não geracional, não discriminatória do ponto de vista étnico-racial.

Mas há ainda uma pergunta, apresentada na seção anterior, que precisa, minimamente, ser respondida no âmbito deste ensaio, qual seja, diante do emaranhado de relações de poder verticalizadas presentes na história do Brasil, a economia capitalista dependente, a gritante desigualdade social, como entender o significado da palavra "solidariedade" a fazer sociedade do ponto de vista de uma seguridade universal?

Tendemos a pensar que mesmo apontando para os avanços no que tange ao discurso solidarista, como pressuposto fundante do novo desenho da seguridade - política setorial, transversal - não é possível deixar 
de lembrar que a solidariedade é um conceito ainda mais amplo do que o em questão, embasado desde o campo jurídico-político.

Um estudo mais amplo sobre o tema da solidariedade precisa considerar o exposto por Razeto (2005) quando apresenta o verbete "Solidaridad" no dicionário de Sociologia. A partir de uma descrição etimológica e uma densa delimitação histórica, apresenta a solidariedade na concepção sociológica e econômica, ressaltando que não é possível construir experiências solidárias pelo simples fato do pertencimento a uma comunidade, a uma ideia. Faz-se necessário, segundo o autor, a presença da corresponsabilidade e de compromissos de permanência no tempo. Nesse sentido, o discurso solidarista que sustenta a seguridade social é limitado e limitante. Para além dos pactos formais, parece-nos que o que pode fazer sociedade na perspectiva da seguridade é a dimensão do controle social. Esse conceito já está presente no SUAS e no SUS, porém, na maioria das vezes, ainda por demais oficial, demasiado mecânico, nem sempre concordante com a ideia de participação social. Haja vista a possibilidade, sempre presente, de que a participação nas instâncias dos governos pode ser cooptada caso a intencionalidade dos operadores da política social não seja de interesse verdadeiramente popular. Não pode haver lugar para a ingenuidade numa esfera em que proteção social/políticas sociais, exploração do trabalho e geração e acúmulo de riqueza constituem uma relação orgânica e não inversamente relacionada.

Assim, à guisa de conclusão, afirmamos que o discurso solidarista vigente necessita abrir-se a paradigmas emergentes desde onde o controle público não seja sinônimo de controle estatal, mas o resultado da participação popular, exercida de fato e direito pelos cidadãos. Há estudos consubstanciais que apontam para essa estratégia de poder popular como uma urgente agenda nacional. Por último, enfatizar que as questões que envolvem direitos sociais mais amplos, na perspectiva da participação e do controle popular, precisam ser objeto de estudo nas salas de aulas das universidades brasileiras porque também se constituem num paradigma emergente, muitas vezes na contramão de como temos conduzido o ensino de nível superior. 


\section{REFERÊNCIAS}

BATICH, Mariana. Previdência do trabalhador: uma trajetória inesperada. São Paulo Perspec. [on-line], 2004, vol. 18, n. 3 [cited 2017-03-05], p. 3340. Disponível em: http://www.scielo.br/scielo.php?script=sci_arttext\&pid =S0102-88392004000300004 . Acesso em: 22 de fevereiro de 2017.

BRASIL. Tribunal Regional Federal da $4^{\text {a }}$ Região. AC 507935052.2014.404.7100, D.E. 06/09/2016 Apelação/Remessa Necessária. RS. Data da Decisão: 31/01/2017. QUINTA TURMA. Relator: (Auxílio Paulo Afonso) TAÍS SCHILLING FERRAZ.

Disponível em https://trf-4.jusbrasil.com.br/jurisprudencia/395806254/

apelacao-remessa-necessaria-apl-50310081020144047100-

-rs-5031008-1020144047100/inteiro-teor-395806302 Acesso em: 02.12.2016.

CAMUS, Albert. O Mito de Sísifo. s.d. Disponível em: http://www.planonacionaldeleitura.gov.pt/clubedeleituras/upload/e_livros/clle000131.pdf Acesso em: $1^{\circ}$. de março de 2017.

CASTRO, Jorge Abrahão de. Política Social no Brasil Contemporâneo. Economia e Sociedade, Campinas, v. 21, Número Especial, p. 1.011-1.042, dez. 2012. Disponível em http://www.scielo.br/pdf/ecos/v21nspe/v21nspea12.pdf Acesso em: 12 de janeiro de 2017.

DELGADO, Guilherme, JACCOUD Luciana e NOGUEIRA, Roberto Passos. Seguridade Social: Redefinindo o alcance da Cidadania [s.d.]. Disponível em: http://repositorio.ipea.gov.br/bitstream/11058/4347/1/bps_n17_vol01_ seguridade_social.pdff Acesso em: 27 de fevereiro de 2017.

FARIAS, José Fernando de Castro. A Origem do Direito de Solidariedade. Rio de Janeiro: Renovar, 1998.

MARX, Karl. O Capital. Crítica da Economia Política. Livro Primeiro. P Processo de Produção do Capital. Tomo 2. Coordenação e revisão de Paul Singer Tradução de Regis Barbosa e Flávio R. Kothe. São Paulo: Nova Cultura, 1996.

OIT. Organização Internacional do Trabalho. ILO. International Labor Organization. Piso de Proteção Social para uma globalização equitativa e inclusiva. Relatório do Grupo Consultivo sobre o Piso de Proteção Social Genebra, Organização Internacional do Trabalho, 2011. Disponível em: http://www.ilo. 
org/public/portugue/region/eurpro/lisbon/pdf/pub_relatbachelet.pdf Acesso em 05.03.2016.

ORNELLAS, Thuê Camargo Ferras de; MONTEIRO, Maria Inês. Aspectos históricos, culturais e sociais do trabalho. Revista Brasileira de Enfermagem. Reben. Rev Bras Enferm. 2006 jul./ago.; 59(4): 552-5. Disponível em: http://www.scielo.br/pdf/reben/v59n4/a15v59n4.pdf Acesso em 12.01.2017.

POLIGNANO, Marcos Vinícius. Histórias das Políticas de Saúde no Brasil. Uma Pequena Revisão. 2001. Disponível em: http://www.ufrgs.br/napead/repositorio/objetos/edital19/gestao-politicas/ARQUIVOS\%20PDF/ Hist $\%$ C3\%B3ria\%20das\%20pol\%C3\%ADticas.pdf Acesso em 05.03.2015.

RAZETO, Luis. Solidaridad. In: Sociología. Chile: Ed. UCSH, 2005.

ROSSO, Paulo Sérgio. Solidariedade e Direitos Fundamentais na Constituição Brasileira de 1988. Revista Eletrônica do CEJUR, a. 2, v. 1, 2, ago./dez. 2007, p. 201-222. Disponível em: http://revistas.ufpr.br/cejur/article/viewFile/16752/11139. Acesso em: 05.12.2016.

SOUZA, Vanessa Alexandre de Souza. As Transformações no Mundo do Trabalho e a Vivência Subjetiva dos Trabalhadores, 2012. Revista Aurora: Marília, p. 25-36. Edição Especial. Disponível em: http://www2.marilia. unesp.br/revistas/index.php/aurora/article/view/2361/1921 . Acesso em: 03 de março de 2017.

SPOSATI, Aldaíza. Proteção Social e Seguridade Social no Brasil. Serviço Social e Sociedade no Brasil. Pautas para o trabalho do assistente social Serv. Soc. Soc. São Paulo, n. 116, p. 652-674, out./dez. 2013. Disponível em: http:// www.scielo.br/pdf/sssoc/n116/05.pdf Acesso em: 04 de março de 2017.

\section{Sobre as autoras}

\section{Patrícia Fontes Marçal}

Doutora em Diversidade Cultural e Inclusão Social. Professora do Curso de Direito da IBgen.

pfmarcal@yahoo.com.br 
Patrícia Fontes Marçal

Dinora Tereza Zucchetti

\section{Dinora Tereza ZucchetTi}

Doutora em Educação. Professora do Programa de Pós-Graduação em Diversidade Cultural e Inclusão Social da Universidade Feevale. Pesquisadora Produtividade do CNPq.

dinora@feevale.br

Submetido em: 5-3-2017

Aceito em: 7-6-2017 